\title{
Identification of factors affecting renewable energy consumption by country groups
}

\author{
Irina Filimonova ${ }^{1,2, *}$, Irina Provornaya ${ }^{1,2}$, and Vladislav Kozhevin ${ }^{1,2}$ \\ ${ }^{1}$ Trofimuk Institute of Petroleum Geology and Geophysics SB RAS, Koptug, 3, 630090, Novosibirsk, \\ Russia \\ ${ }^{2}$ Novosibirsk state university, Pirogova, 1, 630090, Novosibirsk, Russia
}

\begin{abstract}
The rapid development of renewable energy sources observed in recent years however has a number of limitations for different regions limited by non-price factors such as corruption and opacity of supporting institutions, lack the necessary technology to integrate renewable into the grid, lobbying and support of the interests of the owners of traditional energy sources and others. The article attempts to analyse the factors that affect the consumption of renewable energy sources in three groups of countries, pointing to the greater importance of such indicators as the share of R \& $d$ in GDP, the availability of traditional energy resources, oil prices, transparency of institutions for some countries and their lesser importance for others.
\end{abstract}

\section{Introduction}

According to Renewables 2017 Global status report Renewable energy became increasingly cost-competitive compared to conventional thermal generation and by year's end estimated more than $26 \%$ of global electricity generation. Developing and emerging economies provided over half of all investment in 2018. Net capacity additions for renewable power were higher than for fossil fuels and nuclear combined since 2015, and RES now make up more than one-third of global installed power capacity.

The object of the study is renewable energy sources in the fuel and energy balance of the countries.

The purpose of the study is to form recommendations for countries in different clusters based on RES consumption model. The objectives of the study include: 1) analysis of the main trends in RES consumption; 2) identification of factors affecting the level and dynamics of RES consumption based on the econometric model of panel data and cluster analyses and 3) recommendations for policymakers and energy companies in field of RES management. Scientific novelty of research consists of identification of main factors affecting the RES consumption under different clusters of countries, including institutional features of countries, oil prices level, fossil fuels security and the level of technological development; building of multi factor model based on established and systematized indicators with following verification of the significance of factors and making

\footnotetext{
* Corresponding author: filimonovaiv@ list.ru
} 
recommendations for countries. The development of the approach to the use of suggested factors (the prices for fossil fuels - second lag of oil prices, fossil fuels security - the ratio of production to consumption of hydrocarbons, level of institutional sphere development corruption perception index, level of technology development - the share of R \& D in the GDP structure) in the analysis of their impact on RES consumption was presented in our previous paper [1]. This paper will extend this analysis and apply developed model to the several clusters of observed countries.

\subsection{Relevance}

The dominance of traditional fossil energy sources in the coming decades will remain at the same high level, which currently accounts for more than $80 \%$ of total energy consumption. However, the rapid growth of RES gives it a significant place in the global energy balance at the moment. The average annual growth rate of RE + nuclear energy consumption is about $4.3 \%$ over the past 50 years. New renewable energy has been growing at a particularly rapid pace since the early 1990s, mainly represented by solar, wind and biomass energy $-6.5 \%$ is the average annual growth rate of consumption (Fig.1). New renewable energy is starting to play a major role in the development of alternative energy sources, which is due to the physical exhaustion of the potential for growth of hydropower and concerns of some countries about nuclear energy. In General, there is a stagnation in the consumption of nuclear energy in the world according to the production statistics according to the statistics of BP statistical Review.

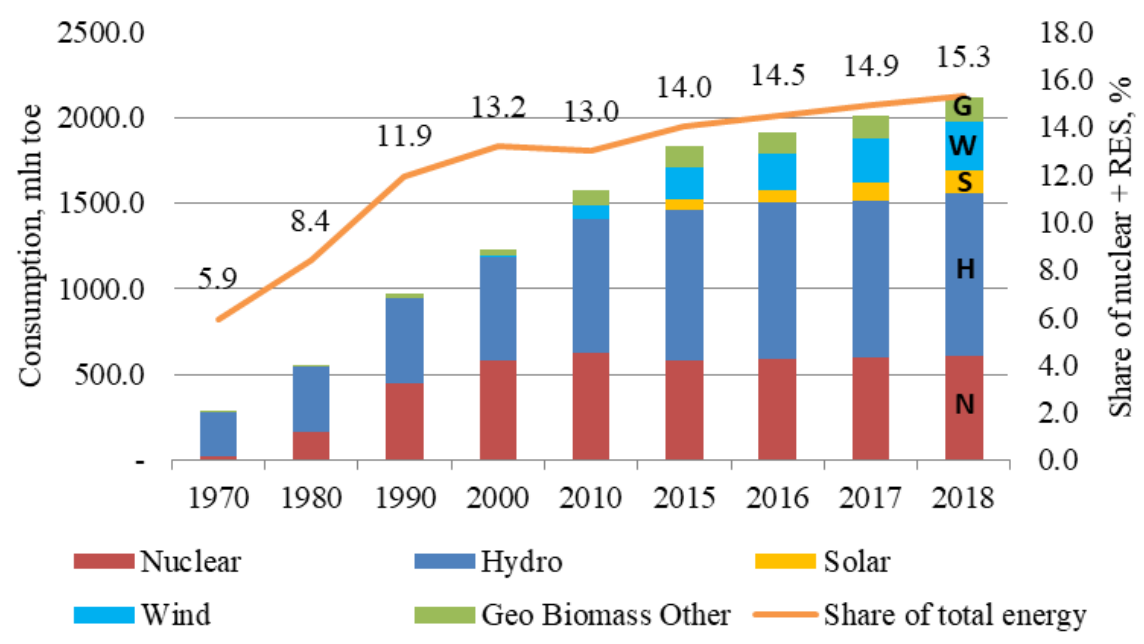

Fig. 1. Dynamics of alternative energy consumption by type in the world.

Now renewable energy start system development in many cities and countries, but the potential low material base effect and ease of use of technology locally can be quite limited by non-price factors such as corruption and opacity of supporting institutions, lack the necessary technology to integrate RE into the grid, lobbying and support of the interests of the owners of traditional energy sources and others. The impact of these factors is noted in the international literature, but the calculation of the economic consequences of such actions is not widely presented. As in previous years, renewables saw far less growth in the heating, cooling and transport sectors, with progress constrained by a lack of strong policy support and by slow developments in new technologies [2]. 


\subsection{Literature}

The study of the influence of various factors both on the consumption of renewable energy and Vice versa has received a fairly broad representation in the literature. The direction that determines the relationship between renewable energy consumption and economic growth is particularly developed. Many studies, including Aiisa, Jebli и Youssef [3], tend to confirm a positive relationship between renewable energy consumption and economic growth. On the other hand, some empirical studies in the context of a demand-based approach, such as Apergis and Payne [4-5], determine the long-term relationship between renewable energy consumption, output, carbon emissions, and oil prices. Most of these studies show that renewable energy consumption has a positive long-term relationship with $\mathrm{CO} 2$ output and emissions, but a minimal or negative relationship with oil prices. Recently, several empirical studies have discussed the long-term role of renewable energy consumption in the macroeconomic context by applying panel co-integration analysis, mainly using FMOLS and DOLS . For example, Sadorsky [6] examines the relationship between renewable energy consumption, income, and electricity prices in emerging market countries during the period 1994-2003 and shows a positive long-term relationship between income and electricity prices and renewable energy consumption. Further, Sadorsky [7] examines the long-term properties of renewable energy consumption in the g-7 countries in the period 1980-2005 and demonstrates that real output and carbon emissions are the key factors determining renewable energy consumption, while oil prices have a small and negative impact on renewable energy sources. Similarly, the work of Salim and Rafiq [8] on six developing countries (Brazil, China, India, Indonesia, the Philippines, and Turkey) during the period 1980-2006 shows that income and carbon emissions are crucial for determining renewable energy consumption, while oil prices have no clear consequences. In addition, Apergis and Payne [5] investigate the role of renewable energy consumption in 11 South American countries between 1980 and 2010 and confirm that real GDP, CO2 emissions, and the real price of oil have positive long-term relationships with renewable energy consumption. Using different approaches to panel co-integration, some papers provide evidence of the importance of renewable energy sources. For example, Apergis and Payne [4] use structural gap analysis and nonlinear error correction models in vector models with a nonlinear panel and find a positive long-term relationship between real GDP, $\mathrm{CO} 2$ emissions, and the real price of oil using renewable energy sources in seven Central American countries during the period 1980-2010. Omri and Nguyen [9] use dynamic panel data analysis to determine the determinants of renewable energy consumption in 64 countries during the period 1990-2011 and show that CO2 emissions are an important factor contributing to increased demand for renewable energy sources, while the price of oil negatively affects only middle-income countries. Models using the following factors are less widely represented in the literature: transparency of the institutes, trade openness, liberalization processes, $R \& D$ processes [10-13]. Based on the above analysis it is necessary, in the opinion of the authors, to focus on several factors significantly affecting the RES consumption and being less studied in the literature - the availability of own oil production, the quality of development of institutions and technologies.

\section{Methodology}

Cluster analysis is a method used to classify objects or events into homogeneous groups, called clusters. Cluster homogeneity means that the objects in each group should be similar to each other and different from the objects in other groups. In this case, the splitting of objects in cluster analysis is allowed not by one parameter, but by a whole set of attributes. 
The Euclidean distance (1) will be used in the framework of the developed model taking into account that it is most often used method and represents the usual geometric distance in multidimensional space (and factors are interval values).

$$
D\left(x_{\mathrm{i}}, x_{\mathrm{j}}\right)=\left(\sum\left(x_{\mathrm{il}}-x_{\mathrm{jl}}\right)^{2}\right)^{\wedge} 0.5, l \in[1, k]
$$

Cluster analysis methods explain the order and technique of cluster formation. All methods can be divided into two groups: hierarchical and non-hierarchical. Hierarchical could be divided into agglomerative and divisive [14]. As a clustering algorithm, the agglomerative clustering of the hierarchical method will be applied, in particular the Ward method, since it gives compact and well separated clusters [15]. On the role of clustering variables will be: GDP per capita, R\&D share in GDP, Renewable consumption, Production to consumption ratio, Transparency index and mix of them. To form comparable and observable across the whole studied period clusters the following measure will be proposed: if cluster do not change significantly in 2016 compare to 2011 , so this way of clustering will be chosen. Under every received cluster, developed RES consumption model will be tested and compared to the overall model [1] for the whole sample of countries. With help of developed cluster approach the cluster distinguishing features will be identified, which allow adjusting the consumption model of renewable energy and their forecasting taking into account the state belonging to a particular cluster. G. Milligan and M. Cooper studied more than thirty rules of cluster number identification [16]. Nevertheless the number of clusters can be determined directly from the analysis goals. For the purposes of the analysis three clusters will be considered. Finally, the resulting groups, depending on the number of clusters, are filtered using R-squares and Fstatistics, where all indicators were previously normalized and combined into a composite indicator (C-value) (2).

$$
C=\sum\left(\mathrm{R}_{2} i \times 0.5+\mathrm{F}_{\mathrm{st}} i\right), i \in[1,3]
$$

where $\mathrm{R}_{2} \mathrm{i}-\mathrm{R}$-square of group $\mathrm{i}$,

$\mathrm{F}_{\mathrm{st}} \mathrm{i}-\mathrm{F}$-statistic of group $\mathrm{i}$.

The highest value of the composite index allows you to determine the most successful combination of factors for selecting clusters. Our example uses three to five indicators as the basis for clustering, which provide twenty-five different ways to group the countries in question. The composite index allows you to determine which of the clustering methods is the most successful.

\section{Results}

\subsection{Data}

To build the model, 37 developed and developing countries were chosen: 21 from Europe, 3 from North America, 1 from former USSR, 2 from Middle East, 1 from Africa, 2 from South America and 7 from Asia-Pacific region.

The data was collected from the OECD databank, World Bank's World Development Indicators, BP statistical review of World energy 2017 and Transparency International's Corruption perceptions index. The observation period under study is between 2006 and 2016, for this period data on the variables was collected. 


\subsection{Empirical testing}

The cluster analysis methodology used is based on the RES consumption model developed in our previous work [1].The resulting model has the following form (3).

$$
\ln (\mathrm{RESC})=a_{1} \times \ln (\mathrm{PC})+a_{2} \times \ln (\mathrm{Oil})+a_{3} \times \ln (\mathrm{CI})+a_{4} \times \ln (\mathrm{RDGDP})
$$

where RESC is the renewable energy sources consumption,

Oil - the price of oil with 2nd lag,

$\mathrm{PC}$ - the ratio of production to consumption,

$\mathrm{CI}$ - corruption index,

RDGDP - share of R\&D in GDP of country.

Clusterization was conducted under five clustering variables: GDP per capita, R\&D share in GDP, Renewable consumption in TW, Production to consumption ratio of oil and gas, and Transparency index. With help of R Studio software 25 clusterization groups were established and estimated with help of model above. Cluster with the highest C-value was selected: Transparency index, Production to consumption ratio of oil and gas and Renewable consumption in TW. One extra check of cluster quality was provided: cluster composition did not change significantly in 2016 compare to 2011, so the 2016 clusterization sample was chosen. Norway were excluded out of the sample because of extremely high Production to consumption ratio of oil and gas, which had an excessive influence on the formation of clusters. So that, Group 1 consists of Argentina, Chile, Czech, Spain, Greece, Hungary, Israel, Italy, South Korea, Mexico, Poland, Portugal, Romania, Russian, Slovak, Turkey, Taiwan, South Africa. Group 2 consists of Australia, Austria, Belgium, Canada, Switzerland, Germany, Denmark, Finland, France, United Kingdom, Ireland, Japan, Netherlands, New Zealand, Singapore, Sweden. Group 3 consists of China and USA. Based on the data for the countries of the world and RES consumption to the whole consumption ratio as dependent variable, three models were built for all three groups of countries: a pooled regression, model with fixed effects, and model with random effects, as previously in paragraph 3.1. Then the most suitable model was chosen by Wald, Breusch-Pagan and Hausman tests - model with fixed effects and this model was assessed for all three groups of countries (Table 1).

Table 1. Assessment of the model under 3 clusters for 36 countries (significance level 0.05).

\begin{tabular}{|c|c|c|c|}
\hline Variable & Group 1 & Group 2 & Group 3 \\
\hline $\begin{array}{c}\text { Logarithm (Production to consumption } \\
\text { ratio) }\end{array}$ & $0.36^{*}$ & $0.21^{*}$ & $1.12^{* *}$ \\
\hline Logarithm (Oil prices 2nd lag) & $1.17^{* * *}$ & $0.87^{* * *}$ & 0.13 \\
\hline Logarithm (Corruption index) & $1.21^{*}$ & -0.18 & 0.66 \\
\hline Logarithm (Share of R\&D in the GDP) & $0.93^{*}$ & 0.40 & $6.58^{* * *}$ \\
\hline $\mathrm{R}^{\wedge} 2$ & 0.52 & 0.58 & 0.96 \\
\hline Adj. R^2 & 0.46 & 0.53 & 0.95 \\
\hline F-statistic & 47.47 & 54.62 & 92.24 \\
\hline Wald & Fixed & Fixed & Fixed \\
\hline Breusch-Pagan & Random & Random & Random \\
\hline Hausman & Fixed & Fixed & Fixed \\
\hline
\end{tabular}

Model is significant, but differ from group to group. For Group 1 all variables are significant at 5\% level, but for Group 2 and Group 3 only two out of four variables are significant at $5 \%$ level.

Most of the countries from Group 1 are located at the bottom of the transparency level list of economies. So that, the corruption level in such countries has an effect on RES consumption. In addition, many countries have a low share of R\&D in GDP, which reduces 
their ability to introduce renewable energy in the country's energy structure, which is why they show a sufficiently positive dependence of renewable energy consumption on $R \& D$ investments - almost one-to-one percent increase. Production of hydrocarbon consumption has the least impact on the consumption of renewable energy in these countries and is significant only due to Russia, Mexico and Argentina with Production to consumption ratio more than 0.9. Contrariwise, 2nd lag of oil prices has the most significant influence on RES consumption, with hydrocarbons being the main substitute for RES: at current time it is cheaper and easier to use. The other thing is that countries already have traditional fuels infrastructure, which is enough difficult to reduce and replace due to lag of investment returns and insufficiently developed energy supply system from RES. Nevertheless, when oil prices climbs up, countries try to reduce costs of usage expensive fuels and reduce theirs' presence in energy balance.

The same thing could be noted for 2 nd Group, where also oil prices strong influence on RES consumption appearing, while the remaining indicators do not have a significant impact: this group of countries has high transparency of the economies and R\&D share in GDP, most of them are developed and eager to change and develop energy infrastructure.

Only two, but leading economies - USA and China, represents third Group of countries. Oppositely to the rest, oil prices and corruption index do not affect RES consumption. Main indicators here are production to consumption ration of hydrocarbons and R\&D share in GDP. The huge scale of these two economies and state support significantly mitigates the effect of corruption on renewables. Moreover, the change in oil prices does not affect the consumption of RES, in the first place, due to the fact, that the consumption of hydrocarbons in these countries comes from the manufacturing sector of the economy, for which the infrastructure of RES is currently not sufficiently developed. At all oil prices, business processes must be carried out. The key finding here is desire to diversify energy sources and reduce the environmental impact of using hydrocarbons. Year by year, the economies of the United States and China are growing and increasing their consumption of energy resources, including hydrocarbons, which occupy a pivotal role in their energy balance. This circumstance not only brings large expenses, but also negatively affects the surrounding nature, which is especially noticeable in the cities of China. When these countries increase the consumption of hydrocarbons, their dependence on these types of fuel increases, which is why countries are forced to diversify their energy balance. Moreover, until recently, both countries were the largest importers of hydrocarbons (the trend has changed for the United States with the development of offshore oil and gas fields). At the same time, their companies and governments invest huge resources in $R \& D$, therefore they are ready and able to develop the infrastructure of renewable energy sources (the more they invest in $\mathrm{R} \& \mathrm{D}$, more sensitive is the consumption of renewable energy to this), and this infrastructure is developing. That is why they are the world leaders in terms of the absolute amount of renewable energy consumption and production.

\section{Discussion}

For countries with low level of transparency and not sufficient R\&D expenditures, it is vitally important to focus on these areas of economic life. Institutions that are more transparent and readiness of the economy for rapid innovation will contribute to the development of renewable energy technologies in countries and, accordingly, their consumption. This is true for the most of the countries from Group 1 and in comparison with countries from Group 2, where such problems are solved. Only co-development of institutions transparency and R\&D will provide maximum results in RES consumption.

For countries with high dependency on production and consumption of hydrocarbons the right decision will be to diversify energy balance and focus on RES capacities 
production, particularly on energy storages and embedding renewables in the infrastructure and economy of the energy sector. Considerable dependence of countries on hydrocarbon prices indicates their impossibility at the moment to abandon the consumption of fossil fuels despite the rapid development of renewable energy sources. Reduction of traditional energy sources will be possible only as a result of upgrading the infrastructure in favour of renewable energy. Accordingly, a deeper introduction of renewable energy sources in the country's institutions is needed. For this group of countries in the present conditions are issues of legal, economic and social field: the relationship between economic agents, pricing issues, the habits of the majority of the population, formation of positive image of RES. For successfully industrialized countries, special attention to R\&D and R\&D in the development of renewable energy in particular will have the greatest effect on increasing their consumption and share in the country's energy balance. USA compare to Group 2 turn out to be more advanced in legal and economic questions of RES what provides targeted financing of high-tech renewable energy projects and determines its leadership positions in RES consumption. Energy companies interested in the development of renewable energy should focus on working together with the state and proposing at least socially beneficial projects especially in countries with low transparency of institutions. In most RES consumption leading countries key steps are taken by the state, convinced of the prospects of renewable energy. Companies must ensure the development of renewable energy technologies through the financing of R\&D and their implementation technologies. Finally, energy companies should be ready to the periods of low fossil fuels prices when consumption of RES could decrease, but in the opposite tendency to have time to get support from states interested in reducing the costs of rising fuel prices, especially in countries where there is a significant need to import hydrocarbons.

\section{Acknowledgements}

The authors are grateful for financial support to Russian Foundation for Basic Research № 18-31020010 and to Grant of the President of the Russian Federation № MK-1819.2020.6.

\section{References}

1. L. Eder, I. Provornaya, I. Filimonova, V. Kozhevin, A. Komarova, Energy Procedia 153, 112-117 (2018)

2. L. Eder, A. Kontorovich, I. Filimonova, I. Provornaya, E. Goosen, SGEM 17(53), 719 726 (2017)

3. M.S.B. Aïssa, M.B. Jebli, S.B. Youssef, Energy Pol. 66, 11-18 (2014)

4. N. Apergis, J.E. Payne, Energy Econ. 42, 226-232 (2014)

5. N. Apergis, J.E. Payne, Energy Sources B Energy Econ. Plann. 10, 281-287 (2015)

6. P. Sadorsky, Energy Pol. 37, 4021-4028 (2009)

7. P. Sadorsky, Energy Econ. 31, 456-462 (2009)

8. R.A. Salim, S. Rafiq, Energy Econ. 34, 1051-1057 (2012)

9. A. Omri, D.K. Nguyen, Energy 72, 554-560 (2014)

10. F. Moliterni, FEEM Working Papers. 33, 27 (2017)

11. A. N. Menegaki, IJEEP 3(4). 321-332 (2013)

12. L. Eder, I. Filimonova, V. Nemov, I. Provornaya, IJEEP, 8(2), 74-80 (2018)

13. C. Isik, M. Radulescu, Statistika: Statistics and Economy Journal, 97(2), 85-94 (2017) 
14. L. Rokach, O. Maimon, Data Mining and Knowledge Discovery Handbook (Springer, 321-352, Boston, 2005)

15. J.H. Ward, J. of the American Statistical Association 58, 236-244 (1963)

16. G.W. Milligan, M.C. Cooper, Psychometrika 50, 159-179 (1985) 